\title{
Micromole per Kilogram per Minute
}

National Cancer Institute

\section{Source}

National Cancer Institute. Micromole per Kilogram per Minute. NCI Thesaurus. Code C126082.

A unit of concentration (molarity unit) equal to one millionth of a mole (10E-6 mole) per kilog ram of a substance per period of time equal to sixty seconds. 